$07,11,13$

\title{
Рост ограненных пор в кристалле по механизму Бартона-Кабреры-Франка
}

\author{
(C) А.В. Редьков \\ Институт проблем машиноведения РАН, \\ Санкт-Петербург, Россия \\ E-mail: avredkov@gmail.com \\ Поступила в Редакцию 16 июля 2019 г. \\ В окончательной редакции 16 июля 2019 г. \\ Принята к публикации 25 июля 2019 г.
}

\begin{abstract}
Рассмотрен рост ограненной поры в кристалле по механизму Бартона-Кабреры-Франка под воздействием механической растягивающей нагрузки. Рост обусловлен диффузией вакансий, содержащихся в кристалле, к террасам и ступеням на поверхности поры. Найдены выражения для скорости продвижения одиночной ступени и группы параллельных ступеней, а также для зависимости нормальной скорости роста поры по спиральному механизму от приложенной нагрузки. Показано, что в определенном диапазоне малых растягивающих нагрузок скорость зависит квадратично от нагрузки, тогда как при больших нагрузках эта зависимость имеет линейный характер. Обсуждается влияние примесей на разрушения кристалла по рассматриваемому механизму роста пор.
\end{abstract}

Ключевые слова: пора, рост, вакансия, кристалл, разрушение, БКФ.

DOI: $10.21883 /$ FTT.2019.12.48559.41ks

\section{1. Введение}

К настоящему моменту создан большой теоретический задел по вопросам прочности и пластичности твердых тел [1-3] ввиду их большой практической значимости. Исследованы различные механизмы разрушения, начиная с классической теории Гриффитса [4], предполагающей исходное наличие микротрещин в материале, которые развиваются со временем. В других теориях и моделях [1,2], получивших развитие в том числе в работах Мотта, Стро, Петча [3] и других авторов, разрушение и образование микротрещин связано с движением и торможением дислокаций у препятствий и взаимодействием различных дефектов решетки. Распространение получила и концепция, основанная на представлениях о формировании зародышей пор из газа вакансий, образующихся под воздействием радиации, либо приложенной нагрузки, детальное описание которой изложено в книге [5], и в цикле статей [6-9]. Основные положения этой концепции заключаются в том, что разрушение кристалла происходит в несколько этапов. На первом этапе в кристалле возникает избыток вакансий под действием растягивающей нагрузки, в результате которого, согласно теории нуклеации [5,7], начинается формирование зародышей пор. После нуклеации наступает стадия роста - поры увеличиваются в размерах за счет притока вакансий из объема кристалла. Затем начинается стадия коалесценции и коагуляции микропоры становятся все больше, поглощая другу друга, и через некоторое время сливаются в макропоры, через которые и происходит разрушение. Такой кинетический подход позволил объяснить зависимость прочности материала от времени нагрузки и дал результаты, близкие к наблюдаемым экспериментально. Отметим, однако, что при рассмотрении эволюции и роста пор в рамках этой концепции, исследователи, в основном рассматривают сферические поры $[5,7,9]$ и диффузионный приток вакансий к ним, но, насколько известно авторам, не уделяют внимание граничной кинетике у поверхности поры. При этом хорошо известно, что растущие поры при малых нагрузках со временем из сферических могут стать ограненными для минимизации поверхностной энергии $[5,10,11]$. В этом случае одним из механизмов их роста может стать классический механизм Бартона-Кабреры-Франка (БКФ) [12], при котором вакансии попадают на террасу на поверхности поры, диффундируют по ней, и встраиваются в ступени и изломы на поверхности. Известно, что при этом механизме перемещение ступеней и рост лимитируются не объемной диффузией, а поверхностной, т.е. с точки зрения объемной задачи о росте поры из газа вакансий рост лимитируются именно поверхностной кинетикой. Поскольку скорость роста микропор пор обуславливает то, насколько быстро произойдет их сливание в макропору и, соответственно, разрушение материала под нагрузкой, теоретическое описание этого этапа роста пор представляется актуальной задачей.

Настоящая работа продолжает цикл работ [6-9,13-15], посвященных росту и эволюции кристаллов и пор в одно - и многокомпонентных системах по различным механизмам, и ее основная цель - рассмотреть рост ограненных пор в кристалле из газа вакансий по механизму терраса-ступень-излом, описанному в класси- 
ческой работе Бартона, Кабреры и Франка [12] и ее многочисленных продолжениях $[16,17]$.

\section{2. Рост поры по механизму БКФ. Постановка задачи}

Рассмотрим кристалл, в котором содержатся поры макроскопических размеров: десятки-сотни микрон и более. Мы считаем, что такие поры имеют огранку. Размеры грани значительно больше характерных расстояний между ступенями и длин свободного пробега вакансий, и при рассмотрении движения отдельной ступени или их группы по террасе, мы можем считать грань бесконечной и пренебречь влиянием ребер поры на распределение вакансий возле ступеней. Предположим, что кристалл подвергается равномерной механической растягивающей нагрузке $\sigma_{0}$ по всей внешней границе. В результате в нем формируются избыточные вакансии, концентрацию $C_{v}$ которых можно записать в виде [7]:

$$
C_{v}=C_{v 0} \exp \left(\frac{\sigma_{0} \omega}{k T}\right),
$$

где $\omega$ - объем приходящийся на одну вакансию, $k$ - постоянная Больцмана, $T-$ температура, а $C_{v 0}=C \exp \left(-\frac{E_{v}}{k T}\right)-$ равновесная концентрация вакансий у плоской границы при данной температуре, $C$ - концентрация атомов в решетке, $E_{v}-$ энергия активации зарождения вакансий. Величина $\sigma_{0}$ считается положительной при растягивающей нагрузке.

Вакансии могут диффундировать по кристаллу и попадать на террасы на поверхности поры. Поскольку, находясь в объеме кристалла, вакансия создает больше оборванных связей, чем находясь на террасе (для простой кубической решетки 6 и 5, соответственно), вакансии энергетически выгодно адсорбироваться на террасе и диффундировать по ней (см. рис. 1). Из-за термических флуктуаций вакансия может оторваться от террасы и снова „испариться“ в объем кристалла [5]. Однако, она может и встроиться в существующие на поверхности поры ступени и изломы „пустоты“, так как это приведет к дополнительному уменьшению свободной энергии. Встраивание в изломы вызывает движение ступеней и постепенное увеличение объема поры.

Задача очень похожа на классический рост кристалла по механизму БКФ [12]. Ключевое отличие от модели

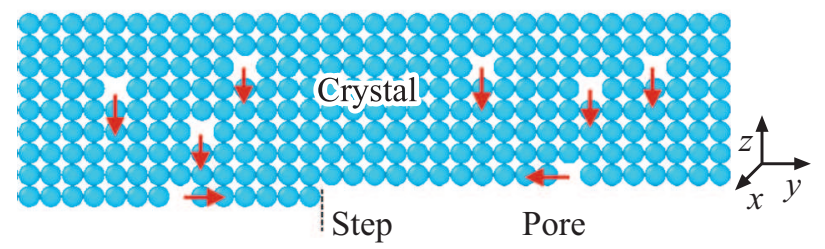

Pис. 1. Схематический вид потока вакансий из объема кристалла на террасы ограненной поры, их диффузия и встраивание в ступень.
БКФ заключается в следующем: в случае роста реального кристалла из раствора концентрация вещества в растворе или паре определяется тем, сколько его физически подают в систему; если речь идет о росте поры (кристалла „пустоты“) из газа вакансий, то концентрация вакансий определяется приложенными упругими напряжениями $\sigma_{0}$ и температурой кристалла [7].

Время жизни до „испарения“ вакансии с террасы и коэффициент диффузии адсорбированной вакансии, можно оценить как [12]:

$$
\begin{gathered}
\frac{1}{\tau_{s}}=v \exp \left(-\frac{W_{s}^{\prime}}{k T}\right), \\
D_{s}=a^{2} v \exp \left(-\frac{U_{s}}{k T}\right),
\end{gathered}
$$

где величины $W_{s}^{\prime}$ и $U_{s}$ - энергии „испарения“ вакансии с поверхности террасы в объем кристалла и энергия активации диффузии вакансии по поверхности террасы. $a$ - длина скачка вакансии (параметр решетки), $v$ - характерная частота атомных колебаний $\left(v \sim 10^{13} \mathrm{~cm}^{-1}\right)$. Длина свободного пробега вакансии по поверхности террасы $\lambda_{s}^{2}=D_{s} \tau_{s}$. Отметим, что равновесная концентрация вакансий на террасе $n_{s 0}=n_{0} \exp \left(-\frac{W_{s}}{k T}\right)$, где $W_{s}-$ энергия перехода вакансии из положения адсорбции на изломе в положение адсорбции на поверхности, а $n_{0} \sim 1 / a^{2}$.

Для того, чтобы найти скорости перемещения отдельной ступени, группы ступеней, а также нормальную скорость роста поры, введем по аналогии с [7,12] пересыщение газа вакансий $\xi$ в объеме кристалла, которое при малой нагрузке $\sigma_{0} \omega \ll k T$ можно записать в виде:

$$
\begin{gathered}
\xi=\alpha-1 \approx \frac{\sigma_{0} \omega}{k T}, \\
\alpha=\frac{C_{v}}{C_{v 0}}=\exp \left(\frac{\sigma_{0} \omega}{k T}\right) \approx 1+\frac{\sigma_{0} \omega}{k T} .
\end{gathered}
$$

Для поверхностного пересыщения $\xi_{s}$ адсорбированных вакансий по аналогии с [12] введем следующие обозначения:

$$
\begin{gathered}
\xi_{s}=\alpha_{s}-1, \\
\alpha_{s}=\frac{n_{s}}{n_{0}} .
\end{gathered}
$$

Сделаем допущение, что подвод вакансий к поверхности поры достаточно эффективен, чтобы поддерживать концентрацию вблизи ее поверхности постоянной $(\xi=$ const). Это справедливо, если температура достаточно высока, присутствует достаточное количество источников вакансий, и скорость их генерации в объеме кристалла, а также обмена с поверхностью поры значительно выше, чем скорость поглощения вакансий ступенями. При этом поверхностное пересыщение $\xi_{s}$ зависит от расстояния до ступени. 


\section{1. Скорость перемещения одиночной ступени}

Рассмотрим одиночную ступень „пустоты“, двигающуюся по поверхности поры. Мы считаем, что ступень достаточно плотно покрыта изломами и является непрерывным стоком для вакансий. Выберем систему координат так, чтобы ось $x$ совпала со ступенью. Пользуясь, математическим аппаратом, разработанным в [12], нетрудно написать уравнение для функции распределения вакансий на террасе около одиночной ступени (см. рис. 1). Поток вакансий $J_{s}$ по поверхности к ступени можно записать как:

$$
J_{s}=D_{s} n_{s} \operatorname{grad} \varphi,
$$

где $\varphi=\xi-\xi_{s}$. Поток вакансий из объема кристалла на поверхность $J_{v}$ по принципу детального равновесия удобно выразить формулой:

$$
J_{v}=\frac{\alpha-\alpha_{s}}{\tau_{s}} n_{s 0}=\frac{n_{s 0} \varphi}{\tau_{s}} .
$$

Пользуясь тем, что функция $\varphi-$ непрерывна, получим уравнение $\operatorname{div} J_{s}=J_{v}$, или

$$
\lambda_{s}^{2} \Delta \varphi=\varphi
$$

Его решением с учетом граничных условий $D_{s} \frac{d \varphi}{d x}=-\left.\beta \omega(\xi-\varphi)\right|_{y=0}$ около ступени (поток может быть ограничен как поверхностной диффузией, так и граничной кинетикой у ступени, $\beta-$ кинетический коэффициент встраивания в ступень), и $\xi_{s}=\xi$ вдали от ступени будет:

$$
\varphi=\xi\left(1+\frac{D_{s}}{\lambda_{s} \beta \omega}\right)^{-1} \exp \left( \pm \frac{y}{\lambda_{s}}\right),
$$

где знаки плюс и минус относятся к нижней и верхней полуплоскостям системы координат соответственно. Пользуясь (3), определим диффузионный поток вакансий к ступени и учитывая, что поток поступает с двух сторон ступени, найдем скорость ее перемещения:

$$
v_{\infty}=\frac{2 J_{s}}{n_{0}}=2 D_{s} \frac{n_{s} 0}{n_{0}} \operatorname{grad} \varphi=2\left(\frac{D_{s} \beta \omega}{\lambda_{s} \beta \omega+D_{s}}\right) \frac{n_{s} 0}{n_{0}} \xi .
$$

Подставляя в полученную формулу зависимость пересышения $\xi$ от $\sigma_{0}$, получим конечное выражение:

$$
v_{\infty}=2\left(\frac{D_{s} \beta}{\lambda_{s} \beta \omega+D_{s}}\right) \frac{n_{s 0}}{n_{0}} \frac{\sigma_{0} \omega^{2}}{k T} .
$$

Из приведенных формул видно, что при сжимающих напряжениях скорость движения ступени отрицательна, поток вакансий направлен от ступени, пора растворяется и уменьшается в размерах. При растягивающих напряжениях, наоборот, поток вакансий направлен к поре, и она растет в размерах.

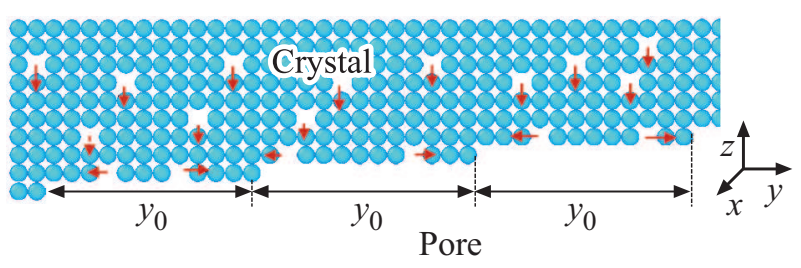

Рис. 2. Схематический вид группы эквидистантных ступеней на поверхности поры, и потока вакансий, поступающих к ним из объема кристалла.

\section{2. Скорость перемещения группы эквидистантных ступеней}

Предположим теперь, что каждая отдельная грань поры содержит значительное число ступеней на своей поверхности, что справедливо, так как характерное расстояние между ступенями на вицинальных гранях кристалла может составлять десятки-сотни нанометров. Будем считать эти ступени эквидистантными, находящимися на расстоянии $y_{0}$ друг от друга (см. рис. 2). Пусть начало координат проходит через центр одной из террас, а ступени по-прежнему параллельны оси $x$. Для нахождения скорости перемещения группы ступеней, согласно [12], необходимо решить уравнение (4) с несколько иными граничными условиями: на середине террасы $(y=0)$ поток адвакансий вдоль оси $y$ равен нулю; у ступени $\left(y=-\frac{y_{0}}{2}\right)$ он может быть по-прежнему ограничен как диффузией, так и кинетикой встраивания вакансий в ступень.

$$
\begin{gathered}
\varphi^{\prime}(0)=0, \\
D_{s} \frac{d \varphi}{d x}=-\left.\beta \omega(\xi-\varphi)\right|_{y=-\frac{y_{0}}{2}}
\end{gathered}
$$

Решением для функции распределения вакансий по рассматриваемой террасе, как нетрудно показать, является:

$$
\varphi=\xi \frac{\beta \omega \lambda_{s} \operatorname{ch}\left(\frac{y}{\lambda_{s}}\right)}{D_{s} \operatorname{sh}\left(\frac{y_{0}}{2 \lambda_{s}}\right)+\beta \omega \lambda_{s} \operatorname{ch}\left(\frac{y}{2 \lambda_{s}}\right)} .
$$

Аналогично предыдущему разделу и [12], найдем поток вакансий к ступени и конечное выражение для скорости перемещения группы ступени:

$$
\vartheta_{\infty}^{g r}=2 \frac{D_{s} \beta \operatorname{th}\left(\frac{y_{0}}{2 \lambda_{s}}\right)}{D_{s} \operatorname{th}\left(\frac{y_{0}}{2 \lambda_{s}}\right)+\beta \omega \lambda_{s}} \frac{n_{s} 0}{n_{0}} \frac{\sigma_{0} \omega^{2}}{k T} .
$$

\section{3. Нормальная скорость роста поры, через которую проходит винтовая дислокация}

В большинстве кристаллов в процессе синтеза формируются различные дефекты, и в частности, винтовые дислокации. В [18] было показано, что винтовая 


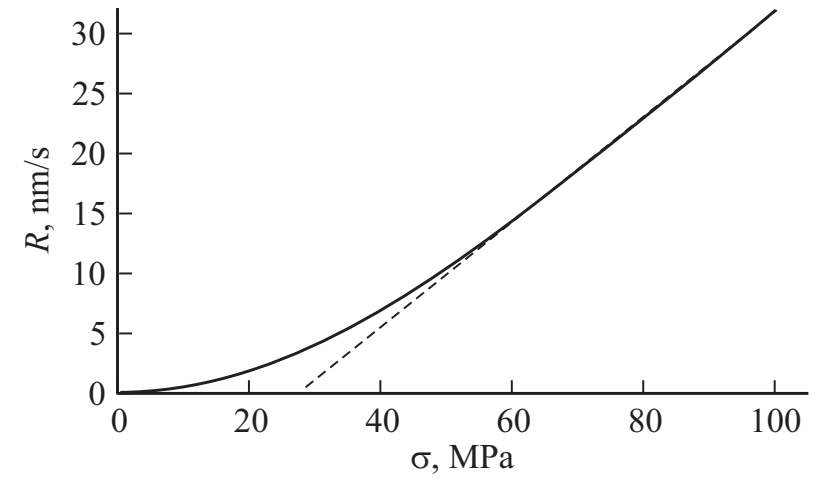

Рис. 3. Зависимость нормальной скорости роста $R$ ограненной поры по механизму БКФ от приложенного растягивающего напряжения (условия см. в тексте).

дислокация может стать непрерывным источником ступеней на поверхности растущего кристалла, и вызвать появление так называемой спирали роста. Именно спиральный механизм является преобладающим при низких пересыщениях, так как нуклеация новых зародышей на поверхности кристалла затруднена. Аналогичным образом, в процессе роста поры может случиться так, что ядро одной из винтовых дислокаций, содержащихся в кристалле, пересечет поверхность поры. В результате на ее грани появится постоянный источник ступеней, который облегчит встраивание новых вакансий, и на поверхности рассматриваемого кристалла „пустоты“ образуются спирали роста, аналогичные наблюдаемым при росте обычных кристаллов. Их можно рассматривать и как обыкновенные ямки травления [19] на внутренней поверхности кристалла, граничащей с порой, однако природа их появления - вакансионная, тогда как появление классических ямок травления вызвано травлением, либо испарением реального вещества с поверхности кристалла.

Нормальную скорость роста поры $R$ (вдоль оси $z$ ) за счет встраивания вакансий в ступени на спиралях роста и „вращения“ спирали можно найти аналогичным [12] образом, подставляя в полученное в предыдущем разделе выражение (5) среднее расстояние между последовательными витками спирали $y_{0}$, которое, согласно [20], определяется критическим радиусом двумерного зародыша $y_{0}=19 \rho_{c}$. В рассматриваемом нами случае $\rho_{c}-$ критический радиус зародыша из вакансий [7]:

$$
\rho_{c}=\frac{\gamma \omega}{k T \ln \xi} \approx \frac{\gamma}{\sigma_{0}}
$$

где $\gamma-$ поверхностная энергия. Таким образом, мы получим следующую формулу для нормальной скорости роста поры:

$$
R=\frac{n_{0} \omega \vartheta_{\infty}^{g r}}{4 \pi \rho_{c}}=\frac{1}{2 \pi \gamma} \frac{D_{s} \beta \operatorname{th}\left(\frac{19 \gamma}{2 \lambda_{s} \sigma_{0}}\right)}{D_{s} \operatorname{th}\left(\frac{19 \gamma}{2 \lambda_{s} \sigma_{0}}\right)+\beta \omega \lambda_{s}} \frac{\sigma_{0}^{2} n_{s 0} \omega^{3}}{k T} .
$$

По аналогии с ростом кристалла по механизму БКФ [12], следует ожидать, что $R$ имеет разную качественную зависимость $\sigma_{0}$ от при различных соотношениях $\frac{19 \gamma}{2 \lambda_{s} \sigma_{0}}$. Действительно, при совсем малых напряжениях $\lambda_{s} \sigma_{0} \ll \gamma$ выражение (6) трансформируется в:

$$
R=\frac{1}{2 \pi \gamma} \frac{D_{s} \beta}{D_{s}+\beta \omega \lambda_{s}} \frac{\sigma_{0}^{2} n_{s} \omega^{3}}{k T}
$$

откуда следует, что $R$ квадратично зависит от приложенного растягивающего напряжения.

При больших напряжениях $\lambda_{s} \sigma_{0} \gg \gamma$ (но все же $\left.\sigma_{0} \omega \ll k T\right)$, гиперболический тангенс в выражении (6) можно разложить в ряд, пренебречь диффузионным членом в знаменателе, и получить линейную зависимость $R$ от величины механических напряжений:

$$
R=\frac{19}{4 \pi} \frac{\sigma_{0} n_{s 0} \omega^{2}}{\tau_{s} k T}
$$

Отметим, что в ряде случаев именно разрастающиеся и перколирующие поры приводят к разрушению материала, и полученные выражения (6-8) дают возможность сделать оценки времени жизни материала до разрушения под воздействием небольших, но постоянных растягивающих нагрузок. Построим зависимость скорости роста поры по выражению (6). Для оценки примем: коэффициент поверхностной диффузии вакансий $D_{s} \sim 10^{-9} \mathrm{~m}^{2} \cdot \mathrm{s}^{-1}$, объем вакансии $\omega \sim 10^{-29} \mathrm{~m}^{2}$, поверхностное натяжение $\gamma \sim 11 / \mathrm{m}^{2}$, температура $T \sim 800^{\circ} \mathrm{C}$. Будем для простоты считать, что вакансии встраиваются в ступень очень быстро $\left(\beta \omega \lambda_{s} \gg D_{s}\right.$, а длина свободного пробега вакансий по террасе составляет порядка $\sim 100 \mathrm{~nm}$. Полученная зависимость приведена на рис. 3. Видно, что при этих условиях переход от квадратичной зависимости $R\left(\sigma_{0}\right)$ к линейной наблюдается при напряжениях порядка 20-40 MPa.

Отметим, что в рамках рассматриваемой модели роста ограненных пор наличие примесей в кристалле может „отравить“ поверхность, аналогично модели КабрерыВермили [21], предложенной для описания роста обычных кристаллов с примесями по механизму „террасаступень-излом“. Таким образом, чтобы активизировать рост поры при наличии примеси, необходимо приложить некоторое критическое напряжение $\sigma_{\mathrm{cr}}$. Оно определяется средним расстоянием между атомами примеси на террасе, проходя через которые, согласно [21], участок ступени изгибается. $\sigma_{\text {cr }}$ соответствует критическому радиусу двумерного зародыша $\rho_{c}$, при котором среднее расстояние между примесями равно $l=2 \rho_{c}$. При напряжениях, меньших $\sigma_{\mathrm{cr}},\left(l<2 \rho_{c}\right.$ изогнутый участок ступени между примесями не сможет преодолеть барьер и продвинуться дальше. Следовательно, добавляя примеси в кристалл, возможно в некотором диапазоне напряжений остановить его разрушение по рассматриваемому механизму. 


\section{3. Заключение}

В работе рассмотрен процесс роста ограненных пор в кристаллических материалах по механизму Бартона, Кабреры и Франка под воздействием небольших механических растягивающих нагрузок. Показано, что рост подобных ограненных кристаллов „пустоты“ полностью аналогичен классическому росту кристалла из паров или растворов и описывается теми же уравнениями, если в качестве источника „пустоты“ рассматривать газ вакансий в кристалле. Найдены уравнения для скорости передвижения отдельных ступеней по террасам кристалла „пустоты“, их групп, а также ступеней, образованных винтовыми дислокациями. Показано, что скорость роста пор, и как следствие, время жизни материала до разрушения зависит от величины механических напряжений. При совсем малых механических напряжениях $\left(\lambda_{s} \sigma_{0} \ll \gamma\right)$, скорость роста поры квадратично зависит от напряжения, тогда как при больших механических напряжениях $\left(\lambda_{s} \sigma_{0} \gg \gamma\right)$ эта зависимость носит линейный характер. Показано, что наличие примесей, аналогично росту обычных кристаллов, может остановить процесс роста поры в некотором диапазоне упругих напряжений. Полученные результаты позволяют сделать оценки о времени жизни материалов до разрушения по рассматриваемому механизму под воздействием небольших, но постоянных растягивающих нагрузок.

\section{Финансирование работы}

А.В. Редьков выражает благодарность за поддержку данной работы Совету по грантам Президента РФ (грант МК-1574.2019.2). Работа частично выполнена при финансовой поддержке программы Президиума РАН „Наноструктуры: физика, химия, биоло-

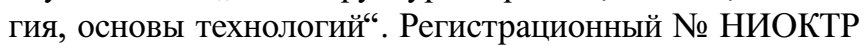
AAAA-A19-119012490107-5.

\section{Конфликт интересов}

Авторы заявляют, что у них нет конфликта интересов.

\section{Список литературы}

[1] Г.П. Черепанов. Механика хрупкого разрушения. Наука, М. (1974). $640 \mathrm{c}$.

[2] В.И. Владимиров. Физическая природа разрушения металлов. Металлургия, М. (1984). 280 с.

[3] Н. Петч. Металлографические аспекты разрушения. Разрушение. Мир, М. (1973). Т. 1. С. 398.

[4] A.A. Griffith. Phil. Trans. Roy. Soc. 221, 163 (1921).

[5] П.Г. Черемской, В.П. Бетехин, В.В. Слезов. Микропоры в твердом теле. Энергоатомиздат, М. (1990). 376 с.

[6] С.А. Кукушкин. Успехи механики 2, 24 (2003).

[7] S.A. Kukushkin. J. Appl. Phys. 98, 033503 (2005).

[8] А.А. Вакуленко, С.А. Кукушкин. ФТТ 40, 1259 (1998).

[9] С.А. Кукушкин, С.В. Кузьмичев. ФТТ 50, 1390 (2008).
[10] M. Kitayama, A.M. Glaeser. J. Mater. Synthesis Proc. 6, 161 (1998).

[11] А.В. Редьков, А.С. Гращенко, С.А. Кукушкин, А.В. Осипов, К.П. Котляр, А.И. Лихачев, А.В. Нащекин, И.П. Сошников. ФTT 61, 433 (2019).

[12] W.K. Burton, N. Cabrera, F.C. Frank. Phil. Trans. Roy. Soc. 243, 299 (1951).

[13] A.V. Redkov, S.A. Kukushkin, A.V. Osipov. J. Phys.: Conf. Ser. 1124, 022006 (2018).

[14] С.А. Кукушкин, А.В. Осипов, А.В. Редьков. ФТТ 56, 2440 (2014).

[15] А.В. Редьков, А.В. Осипов, С.А. Кукушкин. ФТТ 57, 2451 (2015).

[16] A.K. Myers-Beaghton, D.D. Vvedensky. Phys. Rev. A 44, 2457 (1991).

[17] D.P. Woodruff. Phil. Trans. Roy. Soc. 373, 20140230. (2015).

[18] W.K. Burton, N. Cabrera, F.C. Frank. Nature 163, 398 (1949).

[19] K. Sangwal. Etching of crystals: theory, experiment and application. Elsevier, Amsterdam (2012). 496 p.

[20] N. Cabrera, M.M. Levine. Phil. Mag. 1, 450 (1956).

[21] N. Cabrera, D.A. Vermilyea. Growth of Crystals from Solution. In: Growth and Perfection of Crystals / Eds R.H. Doremus, B.W. Roberts, D. Turnbull. Wiley, N. Y. (1958). P. 393.

Редактор Ю.Э. Китаев 